\title{
Assessment of the effectiveness of PMTCT program in eight service delivery points in North Central Nigeria
}

This article was published in the following Dove Press journal: HIVIAIDS - Research and Palliative Care

\author{
Obinna Ositadimma \\ Oleribe' \\ Ede Enenche' \\ Deborah Udofia' \\ Ekei Ekom' \\ Princess Ifunanya Osita- \\ Oleribe ${ }^{1}$ \\ Jin Un Kim² \\ Simon David \\ Taylor-Robinson ${ }^{2}$ \\ 'Excellence and Friends Management \\ Care Centre (EFMC), Abuja, Nigeria; \\ ${ }^{2}$ Hepatology Unit, Imperial College \\ London, London, UK
}

Background: Mother-to-child transmission (MTCT) of HIV is one of the commonest avenues through which infants are infected with HIV. To achieve an HIV-free generation, MTCT of HIV should be eliminated. Nigeria began prevention of mother-to-child transmission (PMTCT) services 13 years ago, but it still contributes to over one-third of global MTCT burden. We set out to explore and define the effectiveness of PMTCT in selected sites in North Central Nigeria. Methods: We conducted a retrospective secondary data analysis at eight service delivery points in two states. One thousand four hundred and fifty-four mother-infant pair data sets from 2012 to 2016 were extracted and analyzed. Maternal/infant antiretroviral (ARV) services, early infant diagnosis (EID), and final outcomes were reviewed to examine the predictors of MTCT of HIV in these centers.

Results: We retrieved 1,454 mother-infant pair data sets. While $89.5 \%(1,302)$ of positive pregnant women (PPW) and 92.2\% $(1,340)$ of HIV-exposed infants (HEIs) received ARV prophylaxis/ARV treatment (ART), 88.4\% (1,285) infants were breastfed with 32.5\% still receiving breast milk at the time of dry blood spot (DBS) collection. EID PCR positivity rate was $3.5 \%$ (range, $0.0 \%-11.1 \%$ ). Facility of delivery $\left(\chi^{2}=24.99, P<0.00\right)$, mother on ARV $\left(\chi^{2}=48.8, P<0.00\right)$, mother having received ARV prophylaxis $\left(\chi^{2}=89.59, P<0.00\right)$, infant having received ARV prophylaxis $\left(\chi^{2}=58.56, P<0.00\right)$, and baby having received cotrimoxazole $\left(\chi^{2}=55.24, P<0.00\right)$ all significantly prevented positive EID results. However, mode of delivery and breastfeeding were not significantly associated with positive EID results.

Conclusion: This study supports PMTCT services as it minimizes the transfer of HIV from infected mothers to HEIs. To eliminate HIV and achieve zero new HIV infections, every HIVpositive pregnant woman should receive ARV prophylaxis and should be supported postdelivery to prevent transfer of infection to the newborn. Also, HEIs should receive timely ARV and cotrimoxazole prophylaxis.

Keywords: antiretroviral therapy, infectious diseases, prevention of mother-to-child transmission, women, Africa

\section{Background}

HIV has remained a major public health challenge, with $\sim 36.7$ (range, 34.0-39.8) million people living with HIV, 1.8 (range, 1.6-2.1) million new infections, and 1 million mortalities by the end of $2016 .^{1}$ To date, over 35 million lives have been lost to HIV and associated infections globally, with sub-Saharan Africa remaining the most affected region, as it accounts for two-thirds of the global total of new HIV infections and with 36.7 million people living with HIV in 2016. ${ }^{1}$ In Nigeria, over 3.1 million people are living with HIV, and the current national HIV prevalence
Correspondence: Obinna Ositadimma Oleribe PO Box 200 PSIN Post Office, Dutse, Abuja, Nigeria

Tel +2348096083335

Email obinna.oleribe@expertmanagers. org 
is $3.0 \%$, according to the recent national sentinel studies, among pregnant women attending antenatal care. ${ }^{2}$

HIV-positive woman can infect their babies during pregnancy, childbirth, and/or breastfeeding, and this accounts for $>90 \%$ of new HIV infections among children. ${ }^{3}$ For instance, in the absence of any interventions during these stages, infected mothers can transmit the virus to their babies in $15 \%-45 \%$ of cases. ${ }^{4}$ In 2015 , there were about 1.8 million children (age, 0-14 years) infected with HIV with 490,000 in West and Central Africa and 260,000 in Nigeria alone. 5,6

Interventions to reduce mother-to-child transmission (MTCT) primarily involve antiretroviral (ARV) treatment (ART) for the mother and a short course of ARV drugs for the baby, measures to prevent HIV acquisition in the pregnant woman, and appropriate breastfeeding practices. ${ }^{4}$ Effective prevention of mother-to-child transmission (PMTCT) services require women-infant pair to have access to all relevant interventions. ${ }^{7}$ In September 2015, the WHO released a new guideline that recommended lifelong ART for all pregnant and breastfeeding women living with HIV, commonly called Option $\mathrm{B}^{+} .8,9$
PMTCT of HIV program began in Nigeria in December 2000 with the inauguration of the PMTCT National Task Team (NTT), while actual PMTCT services commenced as a pilot project in July 2002. This is in line with the WHO four-pronged approach. ${ }^{10}$ However, since inception, no structured evaluation of the effectiveness of the PMTCT services in Nigeria has been undertaken. Therefore, there is a paucity of data on PMTCT effectiveness of PMTCT programs. ${ }^{11}$ The purpose of this study was to determine the effectiveness of PMTCT program in selected sites in Nigeria.

\section{Methods}

We purposefully selected eight supported sites in two states (Nasarawa and Abuja, Federal Capital Territory [FCT]; Figure 1). This study was conducted in sites supported by Excellence and Friends Management Care Center (EFMC), a nongovernmental organization involved in comprehensive HIV health care delivery across a wide range of Nigerian states.

Mothers whose infant details were documented in the registers sufficient for analysis and mothers in care for $>6$ months were included in this study.

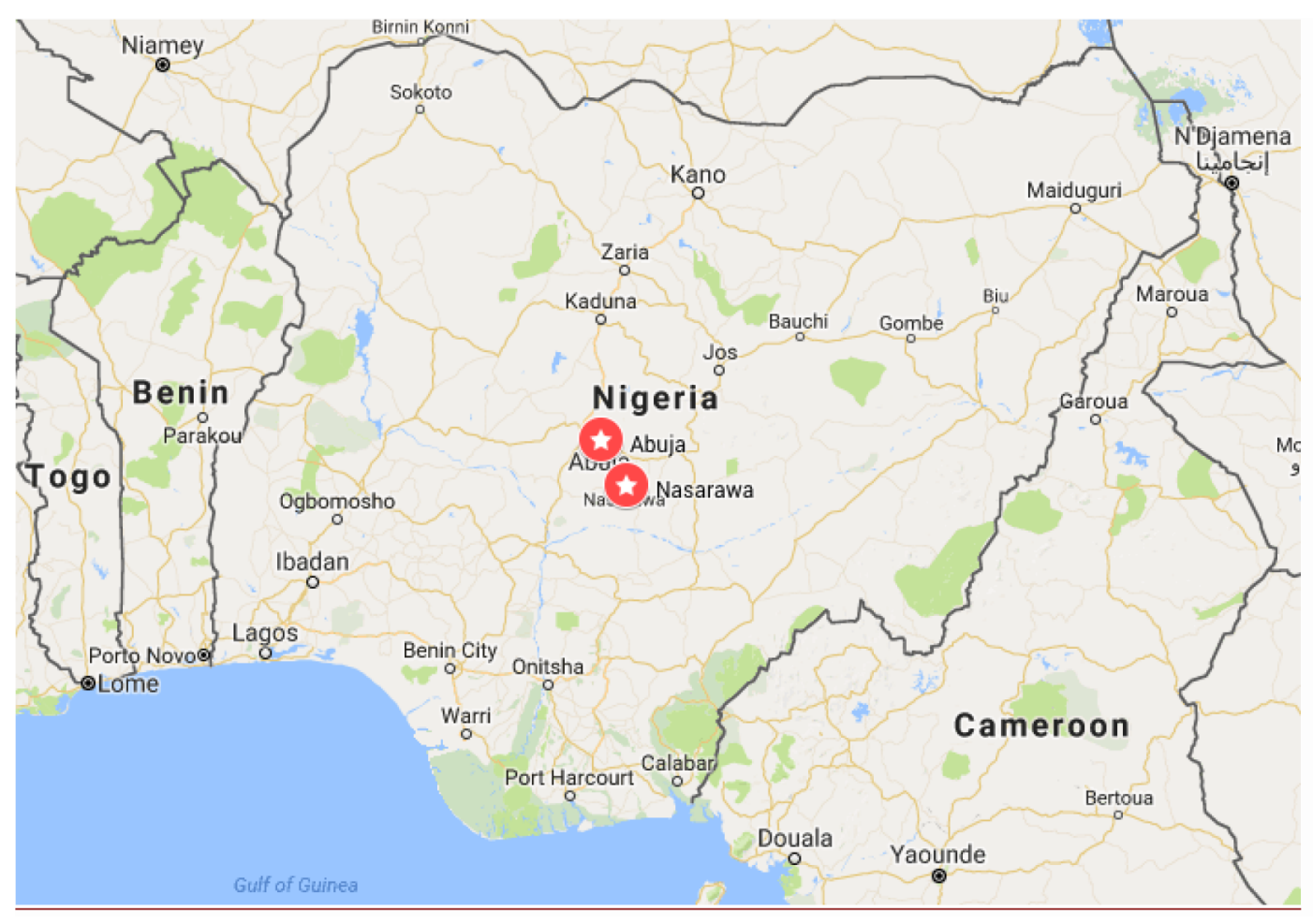

Figure I Map of Nigeria showing study locations - Nasarawa and Abuja, FCT. Abbreviation: FCT, Federal Capital Territory. 
We designed a data extraction form (DEF) using Microsoft Excel spreadsheet to extract and record data. Ethical approval was obtained from the Nigerian Institute of Medical Research (IRB/16/354). All data collected were anonymized to remove identifiers and analyzed in aggregates; therefore, patient consent was not required. The training day included review of the data extraction template, data collection processes, use of Excel sheet, and review of entries. Data collection took place between December 2016 and January 2017. One thousand four hundred and fifty-four data sets were extracted from the early infant diagnosis (EID) PCR request and result forms and the child follow-up register across the eight facilities in the two states. Additional information was obtained from Delivery and Maternal registers. The chisquared test was utilized to test for significance, and data were validated and analyzed using MS Excel, SPSS version 23, and OpenEpi. ${ }^{12,13}$

\section{Results}

A total of 1,454 mother-infant data sets were extracted from the eight health care facilities (seven public and one private) located in Abuja, FCT (7; 87.5\%) and Nasarawa $(\mathrm{n}=1,12.5 \%)$. There were four primary and four secondary level facilities (Table 1), but 1,207 (82.8\%) of the extracted data were from secondary level of care.

There were $50.8 \%$ female infants $(n=738)$ and $48.3 \%$ male infants ( $\mathrm{n}=703)$, with $0.9 \%$ missing gender data $(\mathrm{n}=13)$. The average age of the 1,453 (99.9\%) infants whose ages were properly included in the data set at the time of dry blood spot (DBS) collection was $11.2 \pm 18.1$ weeks with a median and mode of 7 and 6 weeks, respectively. Maternal age range was $18-40$ years.

One thousand four hundred and forty-one (99.1\%) had a documented reason for DBS, with $99.9 \%(1,440)$ being the first test for the healthy exposed baby. One thousand three

Table I Data extraction details from study facilities in Abuja and Nasarawa

\begin{tabular}{|l|l|l|l|}
\hline Facilities & $\begin{array}{l}\text { Level of } \\
\text { care }\end{array}$ & $\begin{array}{l}\text { No } \\
\text { extracted }\end{array}$ & $\begin{array}{l}\text { Frequency } \\
\text { (\%) }\end{array}$ \\
\hline A & Secondary & 116 & 8.0 \\
\hline B & Primary & 53 & 3.6 \\
\hline C & Primary & 17 & 1.2 \\
\hline D & Primary & 51 & 3.5 \\
\hline E & Secondary & 264 & 18.1 \\
\hline F & Secondary & 100 & 6.9 \\
\hline G & Secondary & 727 & 50.0 \\
\hline H & Primary & 126 & 8.7 \\
\hline Total & & $\mathrm{I}, 454$ & 100.0 \\
\hline
\end{tabular}

hundred and two $(91.0 \%)$ mothers were on ARV services. Although 1,166 (93.8\%) positive pregnant women (PPW) received ART, only 445 (37.5\%) PPW started their ART during the index pregnancy, and 1,118 (76.9\%) were placed on triple regimen (Table 2).

One thousand three hundred and forty $(96.5 \%)$ infants received ARV prophylaxis for HIV, 1,285 (92.2\%) were breastfed, and $89.1 \%$ were breastfed exclusively. Extracted data showed that among those with relevant details, $85.4 \%$ were still on breast milk at the time of DBS collection and 91.3\% received cotrimoxazole prophylaxis (Table 3 ).

Table 2 DBS collection and maternal ART details of PMTCT clients in study facilities

\begin{tabular}{|c|c|c|}
\hline & Frequency & Percentage \\
\hline \multicolumn{3}{|l|}{ DBS } \\
\hline Reason for DBS & & \\
\hline $\begin{array}{l}\text { First test for healthy } \\
\text { exposed baby }\end{array}$ & $\mathrm{I}, 440$ & 99.9 \\
\hline First test for a sick baby & I & 0.1 \\
\hline Total & $\mathrm{I}, 44 \mathrm{I}$ & 100.0 \\
\hline \multicolumn{3}{|l|}{ Mother on ART } \\
\hline Yes & 1,302 & 91.0 \\
\hline No & 67 & 4.7 \\
\hline Unknown & 62 & 4.3 \\
\hline Total & 1,431 & 100.0 \\
\hline \multicolumn{3}{|l|}{$\begin{array}{l}\text { Time when ART was } \\
\text { commenced }\end{array}$} \\
\hline \multicolumn{3}{|l|}{ Description } \\
\hline $\begin{array}{l}\text { ART started before } \\
\text { pregnancy }\end{array}$ & 357 & 30.1 \\
\hline $\begin{array}{l}\text { ART started during } \\
\text { pregnancy }\end{array}$ & 445 & 37.5 \\
\hline $\begin{array}{l}\text { ART started after } \\
\text { pregnancy }\end{array}$ & 4 & 0.3 \\
\hline Unknown & 380 & 32.1 \\
\hline Total & $\mathrm{I}, 186$ & 100.0 \\
\hline \multicolumn{3}{|l|}{ Mother receiving ART } \\
\hline Yes & 1,166 & 93.8 \\
\hline No & 23 & 1.9 \\
\hline Unknown & 54 & 4.3 \\
\hline Total & 1,243 & 100.0 \\
\hline \multicolumn{3}{|l|}{$\begin{array}{l}\text { ART regimen for } \\
\text { mothers }\end{array}$} \\
\hline $\begin{array}{l}A Z T / 3 T C / s d N V P \text { in } \\
\text { labor }\end{array}$ & 30 & 2.6 \\
\hline$A Z T / s d N V P$ in labor & 2 & 0.2 \\
\hline Triple regimen & 1,118 & 96.3 \\
\hline Triple regimen & 1 & 0.1 \\
\hline Unknown & 6 & 0.5 \\
\hline None & 3 & 0.3 \\
\hline Total & 1,160 & 100.00 \\
\hline
\end{tabular}

Abbreviations: ART, antiretroviral treatment; DBS, dry blood spot; PMTCT, prevention of mother-to-child transmission; AZT, zidovudine; 3TC, lamivudine; sdNVP, single dose nevirapine. 
Table 3 Infant breastfeeding, ARV, and cotrimoxazole prophylaxis pattern for exposed children in supported sites

\begin{tabular}{|l|l|l|}
\hline Response & Frequency & Percentage \\
\hline Infant prophylaxis & & \\
Yes & $\mathrm{I}, 340$ & 96.5 \\
No & 40 & 2.9 \\
Unknown & 9 & 0.6 \\
\hline Total & $\mathrm{I}, 389$ & 100.0 \\
\hline Infant breastfed & & \\
Yes & $\mathrm{I}, 285$ & 92.2 \\
No & $\mathrm{I} 07$ & 7.7 \\
Unknown & $\mathrm{I}$ & 0.1 \\
\hline Total & $\mathrm{I}, 393$ & 100.0 \\
\hline Mode of breastfeeding & & \\
Exclusive feeding & $\mathrm{I}, 133$ & 89.1 \\
Mixed feeding & $\mathrm{I} 39$ & 10.9 \\
\hline Total & $\mathrm{I}, 272$ & 100.0 \\
\hline Still breastfeeding at & & \\
the time of DBS & & \\
Yes & 472 & 85.4 \\
No & 42 & 7.6 \\
Unknown & 39 & 7.0 \\
\hline Total & 553 & 100.0 \\
\hline Infant cotrimoxazole & & \\
for prophylaxis & & 93.1 \\
Yes & $\mathrm{I}, 092$ & 2.4 \\
No & 28 & 100.0 \\
\hline Unknown & 53 & $\mathrm{I}, \mathrm{I73}$ \\
\hline Total & & \\
\hline
\end{tabular}

Abbreviations: ARV, antiretroviral drug; DBS, dry blood spot.

The first EID HIV positivity rate was $3.5 \%$ as 47 of 1,339 infants tested positive to HIV, and the second EID HIV positivity rate was $1 \%$ among the exposed. Positivity rate for first EID ranged from $0.0 \%$ in three facilities to $11.1 \%$ in one facility $\left(\chi^{2}=24.99, P<0.00\right)$. Mothers who were on ART were statistically less likely to have HIV-infected infants $\left(\chi^{2}=54.71, P<0.00\right)$. Also, infants of mothers who received ARV prophylaxis $\left(\chi^{2}=97.49 .59, P<0.00\right)$, infants who received ARV prophylaxis $\left(\chi^{2}=67.44, P<0.00\right)$, infants who were exclusively breastfed $\left(\chi^{2}=14.07, P<0.00\right)$, and infants who received cotrimoxazole prophylaxis $\left(\chi^{2}=55.97\right.$, $P<0.00)$ were statistically less likely to be HIV infected when compared to the rest (Table 4).

Most deliveries took place in the primary health care center $(61.5 \%)$, followed by secondary facilities $(23.1 \%)$ and maternity homes (14.9\%). Others had their babies at their private homes $(0.8 \%)$. The place of delivery $\left(\chi^{2}=1.49\right.$, $P=0.68$ ) was statistically not significantly related to EID results. From the total birth, 95.5\% were delivered through spontaneous vaginal delivery (SVD). The mode of delivery
$\left(\mathrm{X}_{\text {Yates }}=6.62, P=0.01\right)$ was significantly associated with positive EID results.

The reasons for second EID included repeat test after cessation of breastfeeding $(n=133,85.8 \%)$ and repeat test to confirm the original result ( $\mathrm{n}=12,7.7 \%)$. Other reasons included first testing for the healthy exposed baby and followup for breastfeeding children ( $\mathrm{n}=3,0.9 \%$ each) and repeat testing because of technical problems with the first test $(n=2$, $1.3 \%)$. The rest included first testing for a sick baby and/or to confirm positive PCR.

In the final outcome results analysis, those who became sick or died increased from $1.3 \%$ to $2.7 \%$ between the 6 and 12 months postdelivery.

\section{Discussion}

DBS for HIV PCR was performed on all infants, and in $99.9 \%$ of these infants, DBS was the first test for a healthy exposed baby. The rest were tests for sick babies. The high DBS performance rate is a pointer to quality PMTCT services, as all children from both booked and unbooked mothers were tested for HIV at delivery or soon afterward. Thus, the number of sick infants who were tested for the first time, simply because they were sick, was a very small proportion of the total. However, the majority of the repeat tests was needed after cessation of breastfeeding (85.8\%) and to confirm the first PCR test (7.7\%). This result may be skewed because of lost to follow-up of most infants and their infected mothers. However, this will need further studies for proper elucidation.

As mentioned in previous studies, ART services, ARV prophylaxis, exclusively breastfeeding, and cotrimoxazole prophylaxis protected the HIV-exposed infants (HEIs) from infection before, during, and after birth, and this is statistically significant. ${ }^{3}$ The calculated positivity rate from this study of $3.5 \%$ is well within the acceptable limits. ${ }^{4}$ This is similar to the finding from a South African study ${ }^{11}$ but lower than a similar Nigerian study in 15 supported sites in five states, where the positively rate was found to be $5.3 \%$. Other reported studies from South Africa and Kenya recorded positivity rates of $8.8 \%$ and $10 \%$, respectively. ${ }^{14,15}$

On an individual basis, some sites had no HIV-positive children due to high-quality PMTCT services, while two centers had $8.0 \%$ and $11.0 \%$ positivity rates, respectively. These positivity rates were far higher than the expected $<5 \%$ positivity rate, and the difference between centers was statistically significant. Additional review showed that the majority 
Table 4 Cross tabulation of EID results with various independent variables

\begin{tabular}{|c|c|c|c|c|c|}
\hline & Yes & No & Unknown & Total & Chi square \\
\hline \multicolumn{6}{|c|}{ EID vs mother on ART } \\
\hline HIV negative & 1180 & 51 & 48 & 1279 & \multirow[t]{3}{*}{ 54.7I; $P<0.00$} \\
\hline HIV positive & 27 & II & 6 & 44 & \\
\hline Total & 1207 & 62 & 54 & 1323 & \\
\hline \multicolumn{6}{|c|}{ EID and mother received ART prophylaxis } \\
\hline HIV negative & 1061 & 14 & 39 & 1114 & \multirow[t]{3}{*}{$97.49 ; P<0.00$} \\
\hline HIV positive & 24 & 8 & 7 & 39 & \\
\hline Total & 1085 & 22 & 46 & 1153 & \\
\hline \multicolumn{6}{|c|}{ EID and infant on ART prophylaxis } \\
\hline HIV negative & 1216 & 30 & 7 & 1253 & \multirow[t]{3}{*}{$67.44 ; P<0.00$} \\
\hline HIV positive & 28 & 9 & 2 & 39 & \\
\hline Total & 1244 & 39 & 9 & 1292 & \\
\hline \multicolumn{6}{|c|}{ EID and breastfeeding } \\
\hline HIV negative & 1158 & 98 & I & 1257 & \multirow[t]{3}{*}{$0.04 ; P<0.98$} \\
\hline HIV Positive & 37 & 3 & 0 & 40 & \\
\hline Total & 1195 & 101 & $\mathrm{I}$ & 1297 & \\
\hline & & \begin{tabular}{|l|} 
Exclusive \\
breast feeding
\end{tabular} & $\begin{array}{l}\text { Mixed } \\
\text { feeding }\end{array}$ & Total & \\
\hline \multicolumn{6}{|c|}{ EID and mode of breastfeeding } \\
\hline \multicolumn{2}{|l|}{ HIV negative } & 1025 & 121 & 1146 & 14.07; $P<0.00$ \\
\hline \multicolumn{2}{|l|}{ HIV positive } & 25 & 11 & 36 & $X_{Y_{\text {Yates }}}=12.13 ; P<0.00$ \\
\hline \multicolumn{2}{|l|}{ Total } & 1050 & 132 & 1182 & \\
\hline \multicolumn{2}{|c|}{ 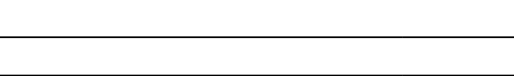 } & Normal & $\mathbf{C} / \mathbf{S}$ & Total & \\
\hline \multicolumn{6}{|c|}{ EID and mode of delivery } \\
\hline \multicolumn{2}{|l|}{ HIV negative } & 55 & 2 & 57 & $6.62 ; P=0.01$ \\
\hline \multirow{2}{*}{\multicolumn{2}{|c|}{$\begin{array}{l}\text { HIV positive } \\
\text { Total }\end{array}$}} & 1 & 0 & I & \\
\hline & & 56 & 2 & 58 & \\
\hline & Yes & No & Unknown & Total & \\
\hline \multicolumn{6}{|c|}{ EID and baby on cotrimoxazole prophylaxis } \\
\hline HIV negative & 999 & 20 & 48 & 1067 & $55.97 ; P<0.00$ \\
\hline HIV positive & 22 & 7 & $\mathrm{I}$ & 30 & \\
\hline \multirow[t]{2}{*}{ Total } & 1021 & 27 & 49 & 1097 & \\
\hline & Home & $\begin{array}{l}\text { Maternity } \\
\text { home }\end{array}$ & $\begin{array}{l}\text { Primary } \\
\text { facility }\end{array}$ & $\begin{array}{l}\text { Secondary } \\
\text { facility }\end{array}$ & \\
\hline \multicolumn{6}{|c|}{ EID and place of delivery } \\
\hline HIV Negative & I & 17 & 73 & 26 & $\mathrm{I} .49 ; P=0.68$ \\
\hline HIV Positive & 0 & $\mathrm{I}$ & 4 & 0 & \\
\hline Total & $\mathrm{I}$ & 18 & 77 & 26 & \\
\hline EID and facility & \multicolumn{5}{|c|}{ Chi Square 24.99; $P<0.00$} \\
\hline
\end{tabular}

Abbreviations: ART, antiretroviral treatment; EID, early infant diagnosis.

of the HIV-positive cases were women who were "unbooked". Booking refers to the initial registration for antenatal care and PMTCT services. Therefore, the majority came into the facility to deliver for the first time and did not receive ARV prophylaxis as a consequence.

Regarding breastfeeding, the latest WHO guidelines recommend the national authorities to promote one infant practice among mothers with HIV, either exclusive breastfeeding while ARV drugs are provided or avoiding all breast milk. ${ }^{16,17}$ The breastfeeding rate $(92.2 \%)$ was higher than findings from other African studies, ${ }^{11}$ which may have been linked to cultural practices that support breastfeeding in Nigeria. However, PMTCT may have helped to improve exclusive breastfeeding to $89.1 \%$ and cotrimoxazole prophylaxis to $91.3 \%$ among the surveyed community against $17 \%$ and $13 \%$ exclusive breastfeeding rate in 2013 and 2008, respectively. ${ }^{16,17}$ Studies have also shown that environmental factors such as access to piped water, electricity, gas, and 
paraffin for fuel, limit the implementation of the $\mathrm{WHO} /$ United Nations Children's Fund guidelines..$^{18}$ This results in inappropriate infant-feeding choices such as mixed feeding and lower infant HIV-free survival. ${ }^{18}$

While the place of delivery was not statistically significantly associated with MTCT, the mode of delivery (cesarean section vs SVD) was statistically significant $(P<0.00)$. Improved tracking of HEIs is needed in PMTCT programs, where access to EID is still limited ${ }^{19}$ as the lowest prevalence of infant HIV infection or death was observed to occur among children completing the cascade. ${ }^{20}$

In this secondary data analysis, adherence, economic costs, the mothers' behavior during highly active antiretroviral treatment (HAART), and the child feeding program during the therapy were not evaluated to ascertain how they could have affected the overall efficacy of ARV services in PMTCT. ${ }^{21}$ These are possible issues to be explored in future studies. Finally, one of the strengths of this study is that the result is free of self-reporting bias (including social desirability bias) seen in other studies where women were asked to self-report their ART use. ${ }^{11}$

Despite the effectiveness of PMTCT services, pediatric HIV infection is still common in Nigeria with the country contributing $>30 \%$ to the global burden of the disease. Several nations in North America and Europe including Cuba have virtually eliminated pediatric AIDS, ${ }^{21}$ but to achieve this in Nigeria, there is the need to periodically assess the effectiveness of the PMTCT program and, based on the findings, modify the strategies and processes in place.

To accelerate PMTCT uptake and ensure that no woman or child is left behind, health care workers should initiate and facilitate provider-initiated and sustained patient counseling (PISC). PISC has five basic components: 1) every pregnant woman should be tested for HIV (and given their results); 2) PPW should be placed on ART or ARV prophylaxis once they are identified during pregnancy or in labor; 3) HEIs should be placed on ARV prophylaxis immediately after birth or at first appearance at a health care facility; 4) all HEIs should receive cotrimoxazole prophylaxis as long as it is required; and 5) HEI should not be breastfed if possible. But if breastfeeding is necessary, exclusive breastfeeding should be encouraged.

\section{Limitations}

PMTCT services in Nigeria are fraught with multiple challenges. In this study, there were missing information from incomplete documentation, lost to follow-up, and delay in result delivery to the facility and to caregivers. Dates were not properly entered and thus were difficult to analyze. This is not unexpected as previous studies have documented the various difficulties encountered (including personnel and infrastructure requirements) with implementing PMTCT and EID services in resource-limited settings, such as Nigeria, which make proper monitored, effective counseling and quality service delivery difficult, if not impossible. ${ }^{16,17}$ Thus, despite the substantial benefits of PMTCT and EID to HIVinfected and HIV-uninfected infants, their families, and programs providing PMTCT services, access to quality services is hindered by these limitations. ${ }^{16,17}$ Only eight sites in two states were analyzed for this study, and therefore, the results are not representative of Nigeria. Although the findings are instructive and should guide programming, there is a need for a wider national survey using nationally representative samples. There will also be the need to compare implementing partners' results, states, and facilities outcomes to identify key challenges and barriers toward eliminating MTCT of HIV in Nigeria.

\section{Conclusion}

Although services have been fully decentralized in Nigeria to primary health care facilities, large number of clients $(82.2 \%)$ still visits the secondary-level facilities, as shown in this study. Improving infrastructures and human resources at the secondary level of care will facilitate the provision of quality and sustainable PMTCT services to pregnant women and supervisory support to linked PHCs. This will culminate in better outcome for all HIV-PPW and HEIs.

To ensure MTCT of HIV is eliminated and impact on the infant minimized, there is a need to make greater efforts to reach all mothers, provide care to all PPW, and screen all HEIs early enough to provide care and treatment to the infected individuals.

\section{Acknowledgments}

We acknowledge the excellent support of all staff and members of Excellence and Friends Management Care Center (EFMC) and management; staff of all supported PMTCT facilities in Abuja and Nasarawa; and Institute of Human Virology, Nigeria (IHVN) for technical assistance in the implementation of this project. SDT-R is grateful to the NIHR Biomedical Facility at Imperial College London for infrastructure support. This study was funded in part by the Wellcome Institutional Strategic Support Fund at Imperial College London. 


\section{Author contributions}

All authors made substantial contributions to conception and design, acquisition of data, or analysis and interpretation of data; took part in drafting the article or revising it critically for important intellectual content; gave final approval of the version to be published; and agree to be accountable for all aspects of the work.

\section{Disclosure}

The authors report no conflicts of interest in this work.

\section{References}

1. United Nations AIDS. Fact sheet - Latest statistics on the status of the AIDS epidemic. [Updated 2017]. Available from: www.unaids.org/en/ resources/fact-sheet. Accessed September 11, 2018.

2. Federal Ministry of Health (FMOH). 2014 National HIV Sero-prevalence Sentinel Survey among Pregnant Women Attending Antenatal Clinics in Nigeria. Department of Public Health National AIDS/STI Control Programme. FMOH, Abuja Nigeria. 2015.

3. de Cock KM, Fowler MG, Mercier E, et al. Prevention of mother-tochild HIV transmission in resource-poor countries: translating research into policy and practice. JAMA. 2000;283(9):1175-1182.

4. World Health Organization (WHO). Mother-to-child transmission of HIV. Available from: http://www.who.int/hiv/topics/mtct/en/. Accessed March 2, 2017.

5. UNICEF. Global Summary of HIV Epidemic among Children (0-14 years), Western and Central Africa, 2015. Available from: https://data. unicef.org/wp-content/uploads/2015/12/2016_West-and-CentralAfrica.xlsx. Accessed March 2, 2017.

6. UNICEF. Nigeria PMTCT Fact Sheet. Available from: http://www. unicef.org/aids/files/Nigeria_PMTCTFactsheet_2010.pdf. Accessed March 2, 2017.

7. Padian NS, Mccoy SI, Karim SS, et al. HIV prevention transformed: the new prevention research agenda. Lancet. 2011;378(9787): 269-278.

8. World Health Organization (WHO). Guideline on when to start antiretroviral therapy and on pre-exposure prophylaxis for HIV; September 2015. [cited March 2, 2017]. Available from: http://www.emtct-iatt.org/ wp-content/uploads/2015/09/WHO-Guidelines-on-When-to-Start-ARTand-PrEP-September-2015.pdf.
9. WHO. Global Guidance on Criteria and Processes for Validation: Elimination of Mother-to-Child Transmission of HIV and Syphilis. World Health Organization; 2014. http://apps.who.int/iris/bitstr eam/10665/112858/1/9789241505888_eng.pdf?ua=1\&ua=1.

10. World Health Organization (WHO). PMTCT strategic vision 2010-2015: preventing mother-to-child transmission of HIV to reach the UNGASS and Millennium Development Goals. Available from: http://www.who. int/hiv/pub/mtct/strategic_vision.pdf.

11. Goga AE, Dinh TH, Jackson DJ, et al. First population-level effectiveness evaluation of a national programme to prevent HIV transmission from mother to child, South Africa. J Epidemiol Community Health. 2015;69(3):240-248.

12. IBM [homepage on the Internet]. Statistical Package for Social Science (SPSS). Available from: http://www.ibm.com/analytics/us/en/technology/spss/. Accessed March 2, 2017.

13. OpenEpi [homepage on the Internet]. Available from: http://www. openepi.com/RbyC/RbyC.htm. Accessed March 2, 2017.

14. Coetzee D, Hilderbrand K, Boulle A, Draper B, Abdullah F, Goemaere E. Effectiveness of the first district-wide programme for the prevention of mother-to-child transmission of HIV in South Africa. Bull World Health Organ. 2005;83(7):489-494.

15. Ngemu EK, Khayeka-Wandabwa C, Kweka EJ, Choge JK, Anino E, Oyoo-Okoth E. Effectiveness of option B highly active antiretroviral therapy (HAART) prevention of mother-to-child transmission (PMTCT) in pregnant HIV women. BMC Res Notes. 2014;7(1):52.

16. TheWorldHealth Organization. Updates onHIV and Infant Feeding. Available from: apps.who.int/iris/bitstream/handle/10665/246260/9789241549707eng.pdf?sequence=1. Accessed April, 2018.

17. Ciaranello AL, Park JE, Ramirez-Avila L, Freedberg KA, Walensky RP, Leroy V. Early infant HIV-1 diagnosis programs in resource-limited settings: opportunities for improved outcomes and more cost-effective interventions. BMC Med. 2011;20;9(1):59.

18. Doherty T, Chopra M, Jackson D, Goga A, Colvin M, Persson LA. Effectiveness of the WHO/UNICEF guidelines on infant feeding for HIV-positive women: results from a prospective cohort study in South Africa. AIDS. 2007;21(13):1791-1797.

19. Ahoua L, Ayikoru H, Gnauck K, et al. Evaluation of a 5-year programme to prevent mother-to-child transmission of HIV infection in Northern Uganda. J Trop Pediatr. 2010;56(1):43-52.

20. Chi BH, Tih PM, Zanolini A, et al. Implementation and operational research: reconstructing the PMTCT cascade using cross-sectional household survey data: the PEARL study. J Acquir Immune Defic Syndr. 2015;70(1):e5-9.

21. Msellati P. Improving access to mother-to-child transmission (PMTCT) programs in Africa: an ongoing process. In: Liamputtong P, editor. Women, Motherhood and Living with HIV/AIDS. The Netherlands: Springer; 2013: 177-187.
HIV/AIDS - Research and Palliative Care

\section{Publish your work in this journal}

HIV/AIDS - Research and Palliative Care is an international, peerreviewed open access journal focusing on advances in research in HIV its clinical progression and management options including antiviral treatment, palliative care and public healthcare policies to control viral spread. The journal is included in PubMed. The manuscript man-

\section{Dovepress}

agement system is completely online and includes a very quick and fair peer-review system, which is all easy to use. Visit http://www.dovepress. com/testimonials.php to read real quotes from published authors. 